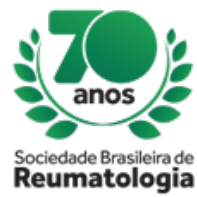

\title{
ANALYSIS OF THE ASSOCIATION BETWEEN STRESS AND RHEUMATOLOGIC SYMPTOMS AMONG
} MEDICAL STUDENTS.

Ana Natália Vasconcelos Arcanjo (Universidade de Fortaleza, Fortaleza, CE, Brasil), Isa Cavalcanti Martildes (Universidade de Fortaleza, Fortaleza, CE, Brasil), Manoella Gotardo Aguiar Gurgel (Universidade de Fortaleza, Fortaleza, CE, Brasil), Victoria Maria Coelho Macedo (Universidade de Fortaleza, Fortaleza, CE, Brasil), Thalia de Souza Bezerra (Universidade de Fortaleza, Fortaleza, CE, Brasil), Kirla Wagner Poti Gomes (Universidade de Fortaleza e Hospital Geral de Fortaleza, Fortaleza, CE, Brasil)

\section{BACKGROUND}

The mental status of health professionals has been a matter of concern since the beginning of the century, given the stressful nature of their work. In addition, medical school is often considered to be prejudicial to the student's mental state. Furthermore, the number of students with rheumatologic complaints is considered quite large, but the prevalence of pain in this population is unknown. This study aims to analyze the relation of the daily stress of medical students with rheumatological complaints.

\section{MATERIALS AND METHODS}

Descriptive cross-sectional study, based on the results of an anonymous online survey, applied through Google Forms, conducted with medical students from the state of Ceará.

\section{RESULTS}

A total of 158 students answered the survey: $74.7 \%$ were female and the average age was 22 years. As for the current semester, $19,6 \%$ were in the sixth, $19 \%$ in the fifth, $18.4 \%$ in the third, and the remainder in the other semesters. $88.6 \%$ studied in private institutions and $11.4 \%$ in public ones. $75.3 \%$ of the participants considered themselves stressed and $60.1 \%$ fully agreed that their academic routine was stressful. As for stress affecting their physical and mental health, $63.3 \%$ totally agreed with that affirmation. In addition, $60.8 \%$ stated that they often could not cope with all of their obligations and only $1.3 \%$ stated that they could. Regarding the symptomatology, $74.7 \%$ presented physical fatigue, $70.3 \%$ back pain, $60.1 \%$ fatigue, $49.4 \%$ low back pain, $41.8 \%$ muscle pain and $23.4 \%$ arthralgia, while only $3.2 \%$ denied any symptoms. Headache, sleep disturbance, neck pain and easy crying have also been reported. $53.8 \%$ fully agreed that worsening of symptoms was associated with academic routine, $78.5 \%$ believed that the onset or aggravation of pain symptoms was associated with stress, $28.5 \%$ performed physical exercises if they experienced pain, $48.7 \%$ did not treat the symptomatology, $27.8 \%$ used medication and $1.3 \%$ had physiotherapy.

\section{CONCLUSION}

There is a high prevalence of stress among medical students in Ceará, and this result is related to their academic routine. Most participants experience symptoms such as pain and believe that stress affects their physical and mental health. Thus, measures that can help change this scenario, such as physiotherapy, exercising and efficient time management are necessary. 